\title{
Desain Model Data Mining Pada Model SECI Untuk Pemetaan Dan Ekstraksi Pengetahuan Kompetensi Lulusan
}

\author{
Mardiani*1 \\ ${ }^{1}$ Universitas MDP; Jln. Rajawali No.14 Palembang, 0711376400 \\ ${ }^{1}$ Program Studi Sistem Informasi, FIKR, Palembang \\ e-mail: *1mardiani@mdp.ac.id
}

\begin{abstract}
Abstrak
Manajemen pengetahuan menggunakan Model SECI membantu dalam transfer pengetahuan tacit dan eksplisit. Keterbatasan kemampuan sumber daya manusia dalam transfer pengetauan membutuhkan alat bantu dalam prosesnya. Ekstraksi pengetahuan dapat dilakukan dengan implementasi data mining. Hasil keluaran data mining yang besar akan dimanfaatkan oleh dunia pendidikan untuk tujuan strategis, misalnya evaluasi penyusunan profil lulusan dari hasil analisis kompetensi lulusan. Kurikulum Program Studi disusun berdasarkan profil Lulusan dan Program Studi membutuhkan pemetaan kebutuhan dari data alumni dalam menyusun kurikulum, sementara alumni membutuhkan mata kuliah yang mendukung setelah selesai kuliah. Manajemen Pengetahuan menampung pengetahuan dari lulusannya, sementara Data mining digunakan sebagai alat dalam mengolah data. Transfer pengetahuan dan pengolahan data kompetensi lulusan, dan memungkinkan munculnya pengetahuan baru bagi perguruan tinggi yang bisa dimanfaatkan dalam proses penyusunan kurikulum berikutnya. Model yang digunakan adalah SECI dikombinasikan dengan algoritma klasifikasi dan clustering. Model SECI yang sudah dipetakan alat bantu teknologinya pada setiap prosesnya, dibuat lebih jelas dan spesifik pengelompokkannya dengan implementasi Data Mining pada setiap kuadran Model SECI. Desain model SECI yang dikombinasikan dengan teknologi Data Mining akan memperbaiki kekurangan yang terdapat pada model sebelumnya.
\end{abstract}

Kata kunci-ekstraksi pengetahuan, model SECI, manajemen pengetahuan

\begin{abstract}
Knowledge management using the SECI Model helps in the transfer of tacit and explicit knowledge. The limited ability of human resources in the transfer of knowledge requires tools in the process. Knowledge extraction can be done by implementing data mining. The output of large data mining will be used by the world of education for strategic purposes, for example evaluating the preparation of graduate profiles from the results of graduate competency analysis. The Study Program curriculum is prepared based on the profile of Graduates and the Study Program requires mapping the needs of alumni data in compiling the curriculum, while alumni need supportive courses after completing college. Knowledge Management accommodates the knowledge of its graduates, while Data mining is used as a tool in processing data. Transfer of knowledge and processing of graduate competency data, and enable the emergence of new knowledge for universities that can be utilized in the process of preparing the next curriculum. The model used is SECI combined with classification and clustering algorithms. The SECI model, which has mapped technological aids in each process, is made clearer and more specific by the implementation of Data Mining in each quadrant of the SECI Model. The design of the SECI model combined with Data Mining technology will correct the shortcomings of the previous model.
\end{abstract}

Keywords — knowledge extraction, SECI model, knowledge management 


\section{PENDAHULUAN}

Pengukuran Kompetensi Lulusan Mahasiswa dapat menggunakan model yang menggambarkan transfer pengetahuan seperti Model SECI. Model SECI memiliki proses yang telah terperinci dan disajikan secara jelas pada setiap kuadran transfer pengetahuan. Penelitian [1] membahas mengenai Perancangan Alat Ukur dan Cara Pengukuran Kompetensi Lulusan Mahasiswa pada Lab Riset Enterprise System And Solution Universitas Telkom Menggunakan Metode SECI. Selain data kuantitatif, Model SECI juga bisa digunakan untuk data kualitatif. Pendekatan kualitatif untuk menganalisis materi empiris dikumpulkan. Pengumpulan data dilakukan dengan memanfaatkan berbagai sumber, termasuk wawancara semi terstruktur, penyebaran kuisioner dan pengolahan dokumen internal [2]. Namun untuk data yang berjumlah kecil atau tanpa menggunakan alat bantu khusus, peneliti kesulitan dalam mengeksplor pengetahuan. Khusus untuk data kuantitatif pemakaian tools dalam bentuk teknologi sangat membantu proses pengumpulan dan pengolahan data. Data Mining dapat diimplementasikan dalam penyebaran pengetahuan dan pengolahan data. Dalam proses manajemen pengetahuan, teknik data mining dapat digunakan untuk mengekstrak dan menemukan yang berharga dan bermakna pengetahuan dari sejumlah besar data.

Saat ini, penambangan data telah memberikan banyak perhatian dan perhatian dalam informasi industri dan dalam masyarakat secara keseluruhan [3]. Sementara untuk alat bantu yang lebih jelas dan lebih detil telah dibahas pada penelitian [4] yang memetakan salah satunya data mining pada proses transfer pengetahuan menggunakan Model SECI.

Model yang digunakan tanpa alat bantu teknologi memiliki kelemahan, diantaranya pada penelitian [1] tahap socialization memiliki kendala pada saat melakukan wawancara untuk mendapatkan tacit knowledge dikarenakan kurangnya pengetahuan dari narasumber terkait dengan alat ukur dan cara pengukuran kompetensi lulusan, sehingga diperlukan penggabungan knowledge dari setiap narasumber agar terpilih alat ukur dan cara pengukuran kompetensi lulusan yang sesuai. Kendala berikutnya, yaitu sulitnya mendapatkan kesempatan untuk melakukan wawancara dengan narasumber, sehingga memerlukan waktu yang panjang untuk mendapatkan tacit knowledge pada tahap ini. Kendala yang ketiga, yaitu sulitnya menerjemahkan kata-kata narasumber yang terkadang tidak sesuai dengan yang diterima, sehingga diperlukan konfirmasi berulang agar tercapai kesesuaian antara penyampaian tacit knowledge dari narasumber dan pemahaman dari pewawancara. Pada tahap externalization memiliki kendala, yaitu terdapat perbedaan knowledge yang dimiliki dari masing-masing narasumber terkait dengan alat ukur dan cara pengukuran kompetensi lulusan. Sementara untuk pemetaan menggunakan model SECI seperti pada penelitian [4] yang memetakan tools dan teknologi apa saja yang bisa dipakai pada setiap proses SECI dari mulai Socialization, Externalization, Combination sampai Internalization digambarkan kurang jelas, karena masih memungkinkan adanya cara lain yang tidak bisa disebutkan semuanya, serta tidak spesifik menyebutkan maksud dari setiap poin tools atau teknologi yang dimaksud.

Tanpa menggunakan bantuan teknologi, proses penyebaran pengetahuan akan mengalami kesulitan karena keterbatasan sumber daya manusia. Sementara dari tools atau IT yang bisa digunakan sebagai alat bantu dalam penyebaran pengetahuan seperti pada penelitian [5] dan [6]. Data Mining setelah melewati tahapan pengolahan data pada Data Warehouse, adalah salah satu poin yang paling bisa diandalkan. Fungsionalitas yang digunakan bisa menggunakan klasifikasi, asosiasi atau clustering dalam pengolahan data. Namun, jika alat bantu yang digunakan tidak dijelaskan dengan spesifik, akan mengurangi nilai prosesnya, dan penelitian selanjutnya tidak akan bisa meneruskan atau mengadopsi metode yang sama. 
Implementasi IT khususnya Data Mining akan mengurangi beban kesalahan yang diakibatkan oleh manusia. Namun pada prosesnya tetap harus dilakukan dengan jelas dan terperinci, agar setiap poin yang dilakukan pada setiap proses pada alur pada Model SECI akan bisa menjamin kebenaran pada proses transfer pengetahuan.

Kompetensi lulusan merupakan hal yang sangat penting untuk diperhatikan oleh Perguruan Tinggi. Mahasiswa harus bisa dipersiapkan untuk bisa bersaing di dunia kerja setelah lulus. Transfer pengetahuan membuka jalan bagi perguruan tinggi untuk memiliki data dan informasi yang nantinya akan bisa dimanfaatkan sebagai pertimbangan ke depannya yang strategis dalam menyusun kurikulum.

Perbaikan Desain Data Mining pada setiap kuadran pada Model SECI dapat membantu kekurangan pada model sebelumnya. Desain model penelitian ini akan memperbaiki model sebelumnya dimana pada setiap proses kuadran di Model SECI perlu ada Data Mining pada setiap prosesnya dan memperjelas posisi algoritma-algoritma Data Mining yang digunakan.

\section{METODE PENELITIAN}

Pembangungan Desain Model Manajemen Pengetahuan dan Implementasi Data Mining, secara umum memiliki kerangka kerja penelitian utama sebagai berikut:

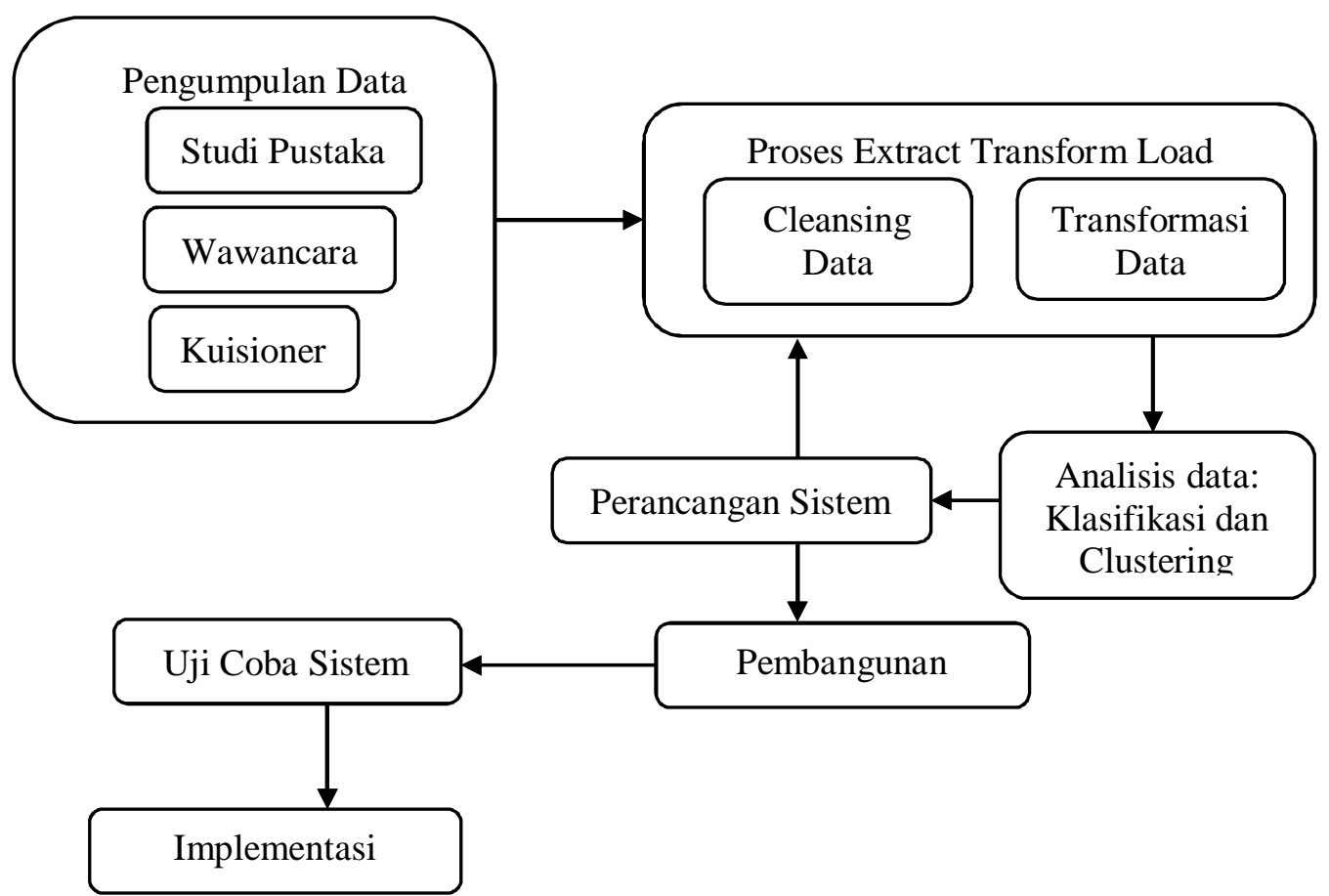

Gambar 1. Kerangka Kerja Penelitian

Tahapan untuk metode penelitian dimulai dengan pengumpulan data. Data digunakan untuk membuat perumusan masalah yang bisa dilakukan dengan cara teknik Pengumpulan Data. Langkah berikutnya yaitu transformasi data, dimana dicari hipotesis dan konklusinya dari data tersebut, proses ini telah masuk ke proses Externalization. Sebelum Preposes data, cleansing data dilakukan, karena data yang didapatkan merupakan data yang masih belum bersih dan harus diolah lagi terlebih dahulu, sebelum memasuki proses data selanjutnya. Setelah data di transformasi atau diolah, kemudian dilanjutkan kepada tahapan analisis data. Dari data training yang telah dianalisis, kemudian dibuat Clustering menggunakan Algoritma K-Means, sebelum 
diprediksi dengan data yang sama. Prediksi klasifikasi menggunakan Algoritma CART untuk kemungkinan-kemungkinan yang akan datang, bagi data testing jenis dan pola yang sama.

Tahapan analisis data, perancangan dan pembangunan sistem, sudah masuk ke dalam tahap Combination. Dimana dari data testing akan didapatkan pola untuk menghasilkan keluaran bagi data trainning. Proses Penemuan menggambarkan data mining sebagai proses penyebaran pengetahuan. Penambangan data bertujuan menemukan pengetahuan atau informasi yang sebelumnya tidak pernah diketahui ada di dalam data.

Proses Internalization dilakukan sebagai proses transfer pengetahuan dari explicit ke tacit. Hal ini dilakukan setelah sistem telah selesai dan diimplementasikan serta diuji. Pengujian hasil dapat dilakukan dengan metode statistik untuk menguji hasil implementasi data mining dan model manajemen pengetahuan yang dibangun sesuai kemudian dilakukan penarikan kesimpulan.

Dari Model yang telah dibangun, dapat dilihat pada setiap proses, tools yang digunakan terdiri atas bagian apa saja. Kemudian yang mana yang bisa cocok dipakai dan masih relevan Pengelompokan dan spesifikasi alat bantu dilihat dari hasil sistem yang dibangun.

\section{PENGGALIAN INFORMASI DAN EKSTRAKSI PENGETAHUAN}

Ekstraksi pengetahuan bertujuan untuk menggali lebih jauh isi dari data dan informasi yang sangat banyak, untuk bisa dimanfaatkan oleh organisasi. Ekstrak pengetahuan dari data untuk keputusan manajerial, menggunakan model khusus yang memiliki rules dan sub rules. Penemuan pengetahuan dan penggalian data interaktif merupakan tantangan masa depan dan arah penelitian. Penggunaan metode Data Mining, memiliki kemungkinan mendapat keuntungan dan kerugian. Pengembangan metodologi penemuan pengetahuan dari data juga bisa dicari, ditemukan dan disajikan, [7] [8] [9].

Penggunaan metode data mining untuk menemukan dan mengumpulkan pengetahuan tersirat dan berharga dari data yang sangat besar dan dimulai dari memaksimalkan pendapatan perusahaan. Penambangan data adalah metode yang ampuh untuk mengekstrak pengetahuan dari data. Data mentah menghadapi berbagai tantangan yang membuat metode tradisional tidak tepat untuk ekstraksi pengetahuan. Penambangan data seharusnya dapat menangani berbagai tipe data dalam semua format [10] .

Pengetahuan tersembunyi memanifestasikan dirinya sebagai hubungan atau pola. [11]

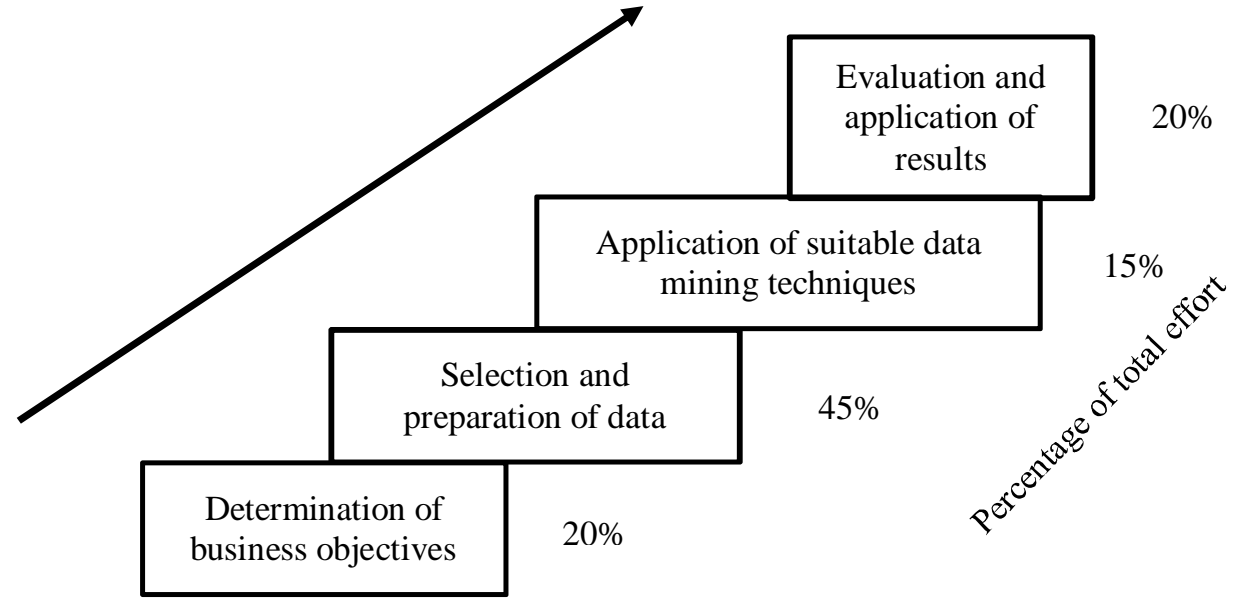

Gambar 2. Knowledge Discovery Phase

(Ponniah, 2001) 


\section{DATA MINING PADA KNOWLEDGE MANAGEMENT}

\subsection{Penggunaan Manajemen Pengetahuan}

Knowledge Management System (KMS) bertujuan untuk meningkatkan kualitas sumber daya manusia dalam suatu organisasi dengan meningkatkan komunikasi antar seluruh bagian organisasi dan meningkatkan perolehan pengetahuan dengan transfer pengetahuan [12].

Proses awal dari Model SECI yaitu Socialization, yang merupakan transfer pengetahuan tacit ke tacit dilaksanakan pada tahap awal pengumpulkan data. Model SECI secara lengkap telah disampaikan oleh Nonaka dan Takeuchi dalam [13]. Ada empat mode konversi pengetahuan:

1. Dari pengetahuan tacit ke pengetahuan tacit: proses sosialisasi.

2. Dari pengetahuan tacit ke pengetahuan eksplisit: proses eksternalisasi

3. Dari pengetahuan eksplisit ke pengetahuan eksplisit: proses kombinasi.

4. Dari pengetahuan eksplisit ke pengetahuan tacit: proses internalisasi

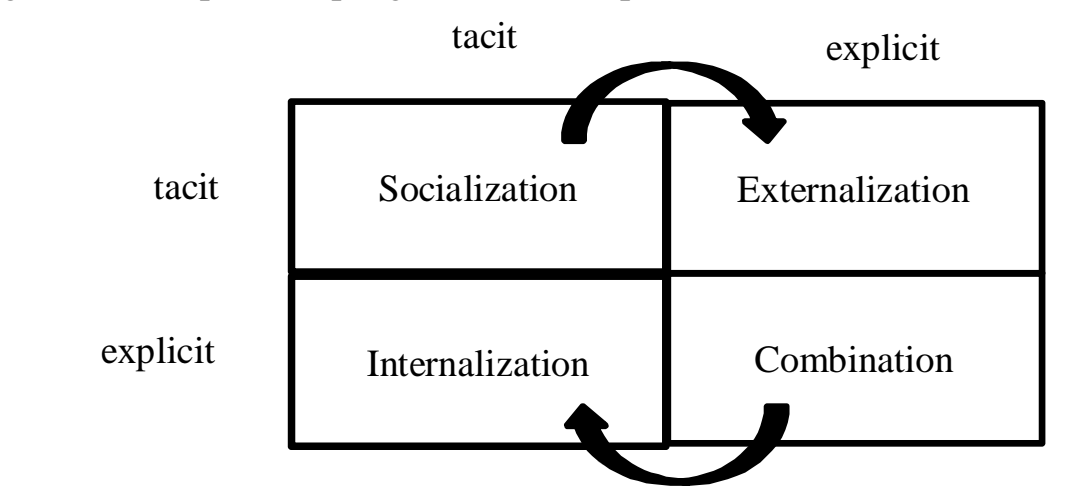

Gambar 3. The Nonaka and Takeuchi Model of Knowledge Conversion

(Dalkir, 2011)

Di bidang manufaktur, digunakan pendekatan baru dan implementasi awal untuk desain berbasis pengetahuan untuk perakitan di agile manufacturing dengan menggunakan metode data mining di bidang produksi dengan varians tinggi [14]. Di bidang bisnis, efek implementasi manajemen pengetahuan dan data mining di industry servis diteliti, serta terdapat review penelitian dan menyarankan integrasi dua teknik data mining: jaringan saraf dan aturan asosiasi dalam pemodelan pemasaran yang dapat berfungsi sebagai masukan untuk manajemen pengetahuan dan menghasilkan keputusan pemasaran yang lebih baik [15] [16].

Membuat model dengan kerangka kerja berbasis manajemen pengetahuan menggunakan data mining juga dilakukan untuk ekstraksi pengetahuan dan penemuan pengetahuan. Prediksi dilakukan untuk menganalisis hasil implementasi atau penerapan strategi manajemen pengetahuan bagi perusahaan [17] [18].

Metode data mining jenis baru dieksplor berdasarkan informasi akses dan algoritmanya untuk sistem manajemen pengetahuan. Proses penemuan pengetahuan dari basis data, teknik data mining dan model dimensi pengetahuan SECI (Sosialisasi, Eksternalisasi, Kombinasi, Internalisasi) menggunakan sistem prototipe manajemen [19]. Aplikasi data mining digunakan sebagai pendekatan data mining untuk pemilihan model dan penemuan pengetahuan. Dengan ledakan informasi di era digital baru, studi penelitian di DM dan KM terus meningkat di organisasi bisnis. DM sangat penting dalam mendukung aplikasi KM karena memproses data menjadi pengetahuan yang berguna dan peran KM selanjutnya, adalah mengelola aset pengetahuan ini dalam organisasi secara sistematis [20]. 


\subsection{Data Mining sebagai Alat Bantu Manajemen Pengetahuan}

Transfer pengetahuan di berbagai bidang, baik untuk pengetahuan tacit maupun explicit, Model SECI dalam membentuk Knowledge Management System pada sebuah organisasi sangat membantu proses alur transfer pengetahuan [2], [21] dan [22]. Transfer pengetahuan tacit ke tacit dalam bentuk sosialisasi, tacit ke eksplisit dalam bentuk eksternalisasi, eksplisit ke eksplisit dalam bentuk kombinasi dan eksplisit ke tacit dalam bentuk internalisasi. Transfer pengetahuan menjadi lebih terarah dan terukur pada setiap kuadran SECI.

Namun Research gap dapat dilihat dari munculnya celah pada kelemahan-kelemahan penelitian yang tidak menggunakan tools seperti [1] yang dimana pada proses transfer pengetahuan kompetensi lulusan terkendala pada kemampuan dan daya tangkap Sumber Daya Manusia, dalam hal ini lulusan dan sering tidak sesuai persepsi antara sumber yang diwawancara dan pewawancara. Kemudian pada penelitian [23] terdapat keterbatasan dalam pengumpulan data karena masalah privasi yang berkaitan dengan nara sumber dan juga penolakan dari beberapa nara sumber untuk berpartisipasi dalam penelitian.

Penelitian yang sudah menggunakan teknologi pun terkendala karena jumlah data sampel yang kecil dan tidak memadai [3] serta tidak setiap implementasi TI cocok untuk setiap tahap model SECI [6]. Data Mining sebagai bagian dari TI telah diimplementasikan seperti paper [4], namun pembahasannya masih belum jelas dan spesifik perlu adanya sub pada poin-poin setiap proses SECI dari Socialization, Externalization, Combination dan Internalization serta pengelompokan dari teknologi-teknologi yang mungkin digunakan.

\section{KESIMPULAN}

Dari celah-celah yang telah dijelaskan sebelumnya, Model sebelumnya seperti yang telah dibahas beberapa paper, memerlukan perbaikan dan revisi. Data Mining memiliki fungsi-fungsi yang lebih spesifik dalam menjelaskan setiap proses transfer pengetahuan. Fungsi-fungsi yang dapat digunakan meliputi fungsi klasifikasi, pengelompokan dan bahkan bisa juga asosiasi. Hal ini akan dapat melengkapi model yang sudah pernah dibuat untuk lebih menjelaskan dan menutup celah dari kekurangan-kekurangan pada penelitian sebelumnya. Desain model dari Data Mining pada Model SECI akan menggunakan algoritma-algoritma terkait dan sesuai pada setiap kuadran model SECI dalam rangka transfer pengetahuan.

\section{DAFTAR PUSTAKA}

[1] R. P. Damario Haznam, Amelia Kurniawati, 2021, "Perancangan Alat Ukur dan Cara Pengukuran Kompetensi Lulusan Mahasiswa pada Lab Riset Enterprise System and Solution Universitas Telkom Menggunakan Metode SECI," Vol. 8, No. 2, pp. 2179-2186,

[2] P. Canonico, E. De Nito, V. Esposito, M. Pezzillo Iacono, and S. Consiglio, 2020, "Knowledge creation in The Automotive Industry: Analysing Obeya-Oriented Practices Using The SECI Model," J. Bus. Res., Vol. 112, No. June, pp. 450-457, doi: 10.1016/j.jbusres.2019.11.047.

[3] S. Natek and M. Zwilling, 2014, "Student Data Mining Solution-Knowledge Management System Related to Higher Education Institutions," Expert Syst. Appl., [Online]. Available: https://www.sciencedirect.com/science/article/pii/S0957417414002462. 
[4] S. Natek and M. Zwilling, 2016, "Knowledge Management Systems Support Seci Model of Knowledge-Creating Process,” Manag. Knowl. Learn. Jt. Int. Conf. 2016 Technol. Innov. Ind. Manag., pp. 1123-1131.

[5] O. Allal-Chérif and M. Makhlouf, 2016, "Using Serious Games to Manage Knowledge: The SECI Model Perspective," J. Bus. Res., Vol. 69, No. 5, pp. 1539-1543, doi: 10.1016/j.jbusres.2015.10.013.

[6] M. Dávideková and J. Hvorecký, 2017, "Collaboration Tools For Virtual Teams In Terms of The SECI Model,” Adv. Intell. Syst. Comput., Vol. 544, No. 1, pp. 97-111, doi: 10.1007/978-3-319-50337-0_9.

[7] M. I. Al-Twijri and A. Y. Noaman, 2015, "A New Data Mining Model Adopted for Higher Institutions,” Procedia Comput. Sci., Vol. 65, No. Iccmit, pp. 836-844, doi: 10.1016/j.procs.2015.09.037.

[8] A. Holzinger and M. Dehmer, 2014, "Knowledge Discovery and Interactive Data Mining In Bioinformatics-State-of-The-Art, Future Challenges and Research Directions." bmcbioinformatics.biomedcentral, [Online]. Available: https://bmcbioinformatics.biomedcentral.com/articles/10.1186/1471-2105-15-S6-I1.

[9] M. Rogalewicz and R. Sika, 2016, "Methodologies of Knowledge Discovery From Data and Data Mining Methods In Mechanical Engineering," [Online]. Available: https://journals.pan.pl/dlibra/show-content?id=106266\&/methodologies-of-knowledgediscovery-from-data-and-data-mining-methods-in-mechanical-engineering-rogalewiczmichal-robert-sika?language $=\mathrm{pl}$.

[10] Y. Bin Xiong and X. F. Zhong, 2013, "Study on Knowledge Management In Process Optimization of Manufacturing Enterprises Based On Data Mining," Appl. Mech. Mater., vol. 416-417, pp. 1381-1387, doi: 10.4028/www.scientific.net/AMM.416417.1381.

[11] P. Ponniah, 2001. Data Warehousing Fundamentals.

[12] W. Hilwa and Samidi, 2014, "Prototype Mobile Knowledge Management System (KMS) for Islamic Banking With 'Tiwana' Framework On University: Case study STEI SEBI," 2014 Int. Conf. Cyber IT Serv. Manag. CITSM 2014, pp. 83-88, doi: 10.1109/CITSM.2014.7042181.

[13] K. Dalkir, 2005. Knowledge Management in Theory and Practice.

[14] R. Kretschmer, A. Pfouga, and S. Rulhoff, 2017, "Knowledge-Based Design For Assembly In Agile Manufacturing by Using Data Mining Methods," Adv. Eng. Informatics, $\quad$ [Online]. Available: https://www.sciencedirect.com/science/article/pii/S1474034616301586.

[15] S. K. Srivastava, B. Chandra, and P. Srivastava, 2019 "The Impact of Knowledge Management and Data Mining On CRM in The Service Industry," Nanoelectron. Circuits, [Online]. Available: https://link.springer.com/chapter/10.1007/978-981-130776-8_4. 
[16] M. Zekić-Sušac and A. Has, 2015, "Data Mining As Support to Knowledge Management in Marketing,” Bus. Syst. Res. J., Vol. 6, No. 2, pp. 18-30, doi: 10.1515/bsrj-2015-0008.

[17] P. Ristoski and H. Paulheim, 2016, "Semantic Web In Data Mining and Knowledge Discovery: A Comprehensive Survey," J. Web Semant., [Online]. Available: https://www.sciencedirect.com/science/article/pii/S1570826816000020.

[18] L. Sadath, 2013, "Data Mining: A Tool for Knowledge Management In Human Resource,” International Journal of Innovative Technology. Citeseer, [Online]. Available: http://citeseerx.ist.psu.edu/viewdoc/download?doi=10.1.1.681.3330\&rep=rep1\&type=pdf

[19] Y. D. Guo, 2013, "Prototype System of Knowledge Management Based On Data Mining," Appl. Mech. Mater., Vol. 411-414, pp. 251-254, doi: 10.4028/www.scientific.net/AMM.411-414.251.

[20] Y. Li, M. A. Thomas, and K. M. Osei-Bryson, 2017, “Ontology-Based Data Mining Model Management For Self-Service Knowledge Discovery,” Inf. Syst. Front., [Online]. Available: https://link.springer.com/article/10.1007/s10796-016-9637-y.

[21] Charlote K. Faith and A. K. Seeam, 2018, “Knowledge Sharing In Academia: A Case Study Using a SECI Model Approach Knowledge Sharing In Academia : A Case Study Using A SECI Model Approach,” J. Educ., Vol. 9, No. June, pp. 52-70.

[22] M. L. Farnese, B. Barbieri, A. Chirumbolo, and G. Patriotta, 2019, "Managing Knowledge In Organizations: A Nonaka's SECI Model Operationalization," Front. Psychol., Vol. 10, No. December, pp. 1-15, doi: 10.3389/fpsyg.2019.02730.

[23] A. M. Obeidat, 2019, "IT Adaption With Knowledge Conversion Process (SECI)," Manag. Sci. Lett., Vol. 9, No. Spceial Issue 13, pp. 2241-2252, doi: 10.5267/j.msl.2019.7.029. 